\title{
Comparative study on porous media combustion characteristics using different discrete materials
}

\author{
Ayub Ahmed Janvekar', M. Z. Abdullah², Z. A. Ahmad ${ }^{3}$, Aizat Abas ${ }^{1}$, Musavir Bashir², Mazlan Mohamed ${ }^{1,4}$ \\ ${ }^{1}$ School of Mechanical Engineering, Universiti Sains Malaysia, Engineering Campus, 14300 Nibong Tebal, Penang, Malaysia \\ ${ }^{2}$ School of Aerospace Engineering, Universiti Sains Malaysia, Engineering Campus, 14300 Nibong Tebal, Penang, Malaysia \\ ${ }^{3}$ School of Materials and Mineral Resources Engineering, Engineering Campus, 14300 Nibong Tebal, Penang, Malaysia \\ ${ }^{4}$ Advances Material Research Cluster, Faculty of Bioengineering and Technology, Universiti Malaysia Kelantan, Jeli Campus, 17600 Jeli, \\ Kelantan, Malaysia
}

\begin{abstract}
Occurrence of combustion phenomenon in porous media has always excited researchers to develop various shape and size of burner so that maximum utilization of energy can be taken achieved. Here in this experiential work, dual layer micro burner was exclusively built to carry out porous media combustion characteristic with different type of discrete material in reaction zone. Presently, only alumina and zirconia are compared in discrete form, while preheat layer was made of porcelain ceramic material (foam type). Reaction zone was restricted to thickness of $20 \mathrm{~mm}$ while preheat zone at $10 \mathrm{~mm}$. A concept of equivalence ratio was aided since it involves premixed combustion of air and butane as fuel mixture. Additionally, burner was made to run under lean to ultra-lean modes and finest temperature were recorded. Both surface and submerged flame was generated effectively. Maximum temperatures recorded during surface and submerged flame condition was better by installing alumina rather than zirconia there by reaching a value of $631^{\circ} \mathrm{C}$ and $470^{\circ} \mathrm{C}$ respectively. Thus maximum thermal efficiency was calculated and found out to be $84 \%$. Finally, emission parameters like NOx and $\mathrm{CO}$ where monitored and found out to be well within acceptable limits.
\end{abstract}

\section{Introduction}

Impact of fossil fuel in developing countries will not only affects industrial and domestic sector but greatly endeavour in economic aspects of nation. Thus saving single drop of fuel either in crude or purified state becomes very much necessary [1-3]. Now to identify the large scale consumption of fuel need to snipped surveyed by grassroots level. So by and large burners one of the vital candidate for consuming large amount of fuel. Burners are not only used in domestic sector to fulfil day to day requirements of the peoples, but does act as prime source of energy supply in medium and large scale industries. Tremendous research work has already been carried out in the area of modern burner developments, but there is wide scope to build novel burner with high thermal efficiency [4-6]. Fusing porous media and burner together have created significant results in downgrading the emissions and enhancing the temperature profiles. Addition of porous media in reaction zone shall increase the combustion surface area exponentially their by generating high thermal energy [7-9]. Premixed combustion is popular over non premixed combustion especially with portable, macro and micro burner. Zuo, E [10] worked on micro elliptical tube combustor and compared with regular micro circular tube combustor and focused on the understandings of the combustion characteristics. It is found that the pressure loss and combustion efficiency of the micro elliptical tube combustor is larger than that of the micro circular tube combustor. Panigrahy, Mishra [11] made numerical and experimental analyses of combustion of LPG in a domestic cooking stove with a two-layer porous radiant burner, and conveyed $\mathrm{CO}$ emissions of all burners operating at equivalence ratio (ER) 0.4 or below were found to be lower than $5.0 \mathrm{ppm}$. Mustafa, Abdullah [12] made a combustion driven thermoelectric (TE) and thermophotovoltaic (TPV) power systems using several blends of vegetable cooking oil-kerosene (VCOK) fuels and moreover enabled TE and TPV systems with a porous burner. Restrict their study to combustion characteristics and system performance. Ismail, Abdullah [13] work with porous medium burner (PMB) along micro cogeneration system. The average surface temperature obtained in this study was $544.8^{\circ} \mathrm{C}$ for a flow rate of $0.25 \mathrm{~L} / \mathrm{min}$. Impact of using butane have also shown significant improvement in porous media burners $[14,15]$. Present work deal with compassion between utilization of alumina and zirconia porous media in reaction layer. Both surface and submerged flame conditions were taken into account. Burner was made to run from lean to ultra-lean equivalence ratio. Finally, generated emission was fed into chimney to calculated the amount of NOx and CO. 


\section{Experimental setup}

With the help of professional drawing tool burner housing was sketched was as shown in Fig. 1. It helps to understand the major components of the housing. A complete layout of the system is as shown in Fig. 2 whereas actual setup is as shown in Fig. 3.

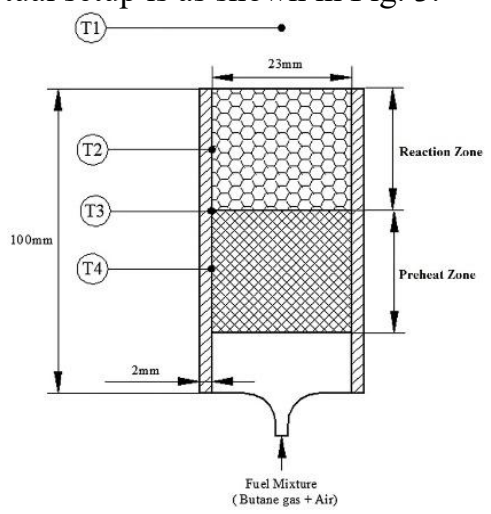

Figure 1. Sectional view of burner housing. (Not to scale).

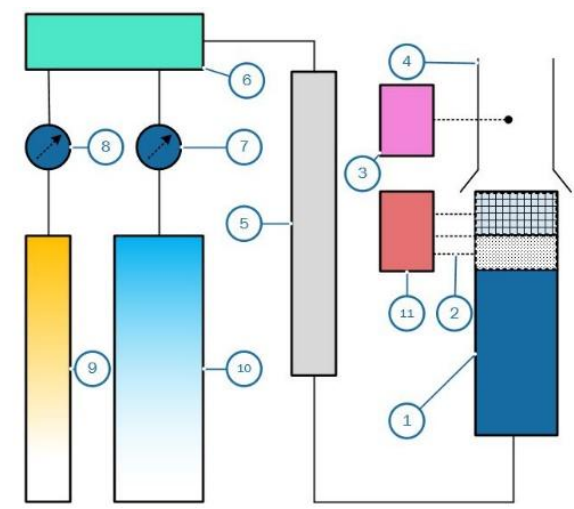

Figure 2. Layout of combustion system. (1) Housing, (2) Thermocouple, (3) Emission gas analyser, (4) Gas conduit, (5) Mixing unit, (6) Pre-mix, (7) Air flow meter, (8) Butane flow meter, (9) Butane supply, (10) Air inject, (11) DAQ (Data acquisition system).

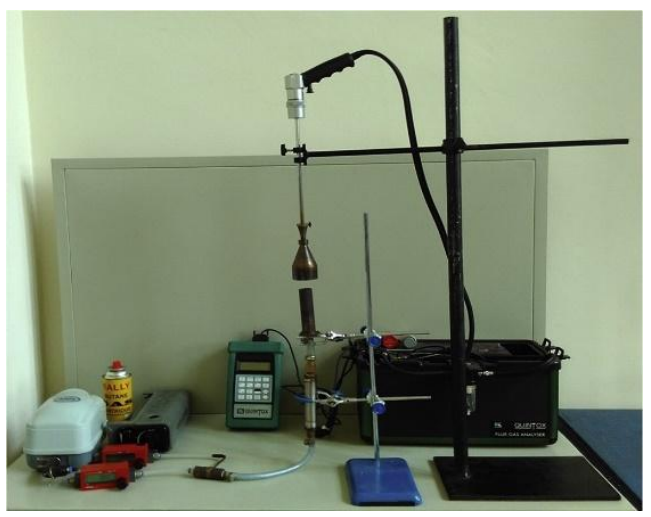

Figure 3. Experimental burner setup.

Burner housing was divided into two major sections namely upper section (Reaction zone) and lower section (Preheat zone). Thickness of reaction zone was freeze to $20 \mathrm{~mm}$ while the preheat at $10 \mathrm{~mm}$. Corresponding experimental trial were taken with both alumina and zirconia in upper section. Whereas porcelain in the foam type was maintained in lower section. Preheat layer was made of porcelain foam with 8 ppcm and a porosity of $84 \%$. Premixing was perfumed using two pre mix units as shown in layout. Butane was supplied from compressed butane cartridge, while air was regulated with domestic natural gas pump. Both fuel and air was controlled using certified digital flow meters. Fuel mixture was introduced from the bottom of the burner housing. Thermocouple (K-type) was used to measure surface temperature (T1) while surface probe was used to for wall temperature at suitable locations (namely T2, T3, and T4). T1 was placed at mid of reaction zone, $\mathrm{T} 2$ at the junction between reaction and preheat layer while T3 at the mid of preheat layer. To capture the behaviour of the $\mathrm{K}$ type of thermocouple DAQ system was also used, which help to generate the accurate results vai computer. At critical ER, thermal images where taken with FLUKE thermal imager. Flow of air and butane was measure L/min while emissions were captures using KANE-9106 QUINTOX Combustion Analyser in ppm (parts per million).

\section{Analysis}

Present work deals with natural air, concept of ER was used as shown in Equation (1), where the actual air-fuel ratio $\left(\mathrm{M}_{\mathrm{a}}\right)$ and while stoichiometric air fuel ratio $\left(\mathrm{M}_{\mathrm{s}}\right)$ for butane gas, was can be calculated by considering Avogadro's and Dalton's laws [13], which was computed a value of 30.95 with air at room temperature as shown in Table 1 .

$$
\mathrm{ER}=\mathrm{M}_{\mathrm{s}} / \mathrm{M}_{\mathrm{a}}
$$

Table 1. ER for butane and air flow rate.

\begin{tabular}{|l|c|c|c|c|c|}
\hline Butane (Lpm) & \multicolumn{5}{|c|}{0.1} \\
\hline Air (Lpm) & 3.1 & 3.4 & 3.8 & 4.4 & 5.1 \\
\hline ER & 1.0 & 0.9 & 0.8 & 0.7 & 0.6 \\
\hline
\end{tabular}

Stable flame with minimum fuel consumption was obtained at $0.1 \mathrm{Lpm}$ (litre per $\mathrm{min}$ ). Trails were performed at room temperature. With alumina in reaction zone, maximum surface temperature was noted as $631^{\circ} \mathrm{C}$ at $0.7 \mathrm{ER}$, while zirconia it was around $615^{\circ} \mathrm{C}$ at $0.7 \mathrm{ER}$, as shown in Fig 4. and 5. Average temperature profile can be seen in Fig. 6 and 7 .

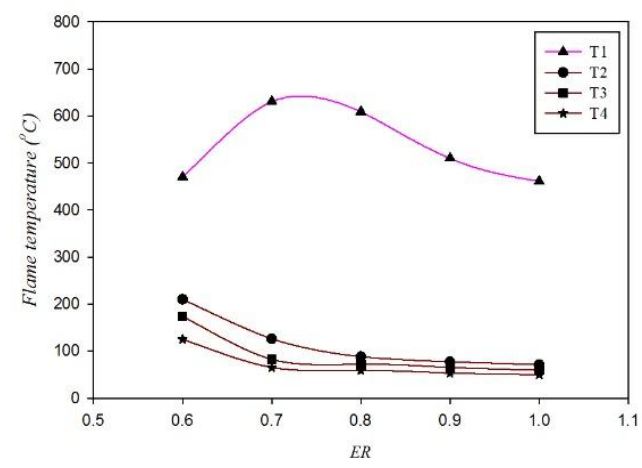

Figure 4. Flame temperature for alumina 


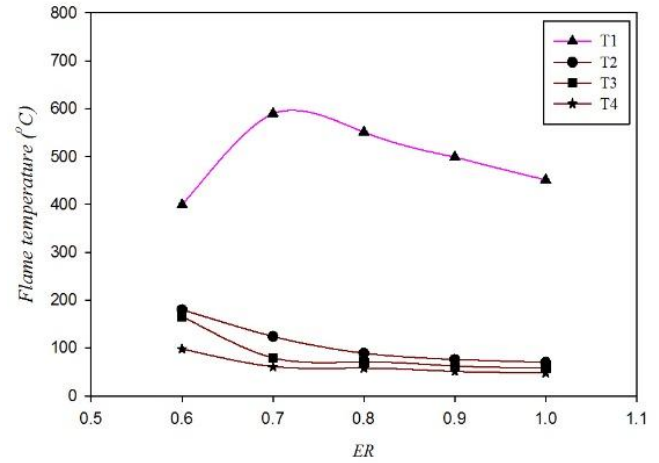

Figure 5. Flame temperature for zirconia

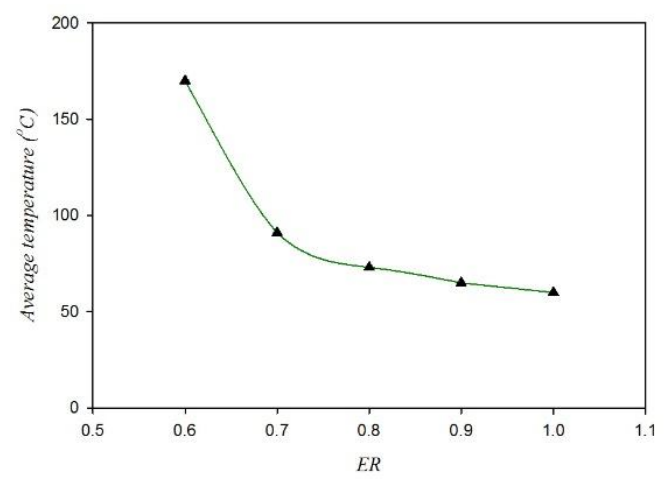

Figure 6. Average temperature for alumina

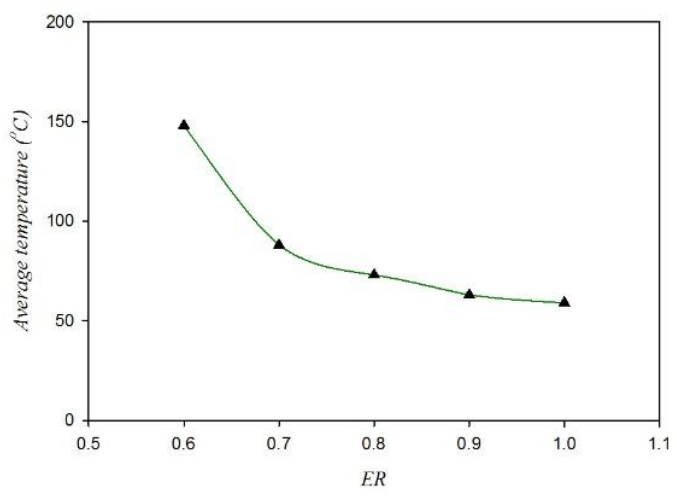

Figure 7. Average temperature for zirconia
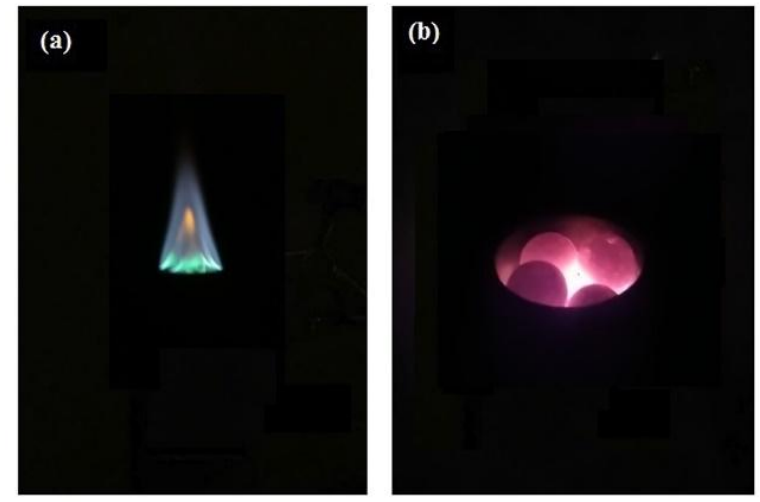

Figure 8. Surface (left) and submerged flame (right)

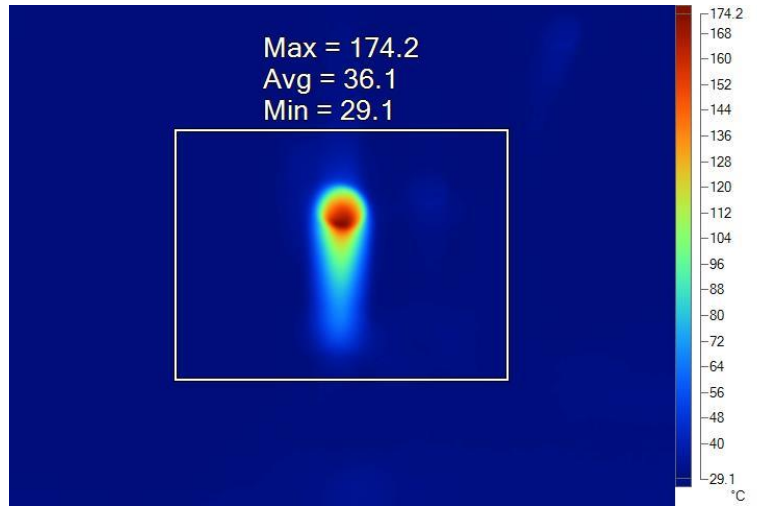

Figure 9. Thermal image with alumina in reaction zone

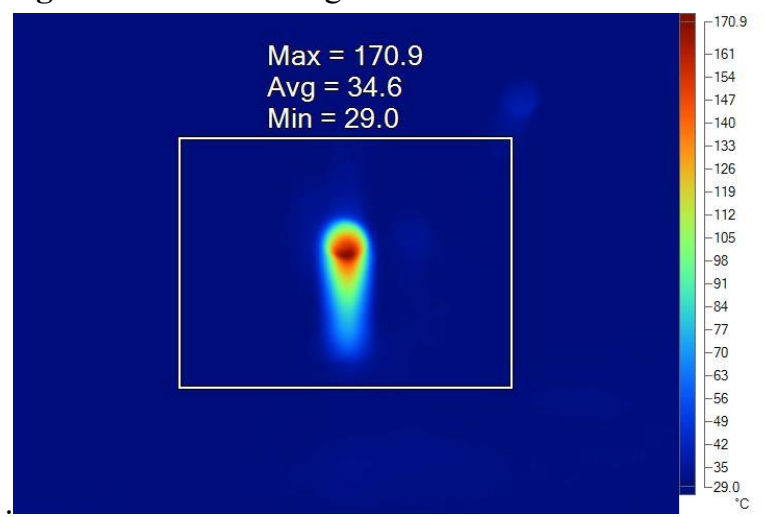

Figure 10. Thermal image with zirconia in reaction zone

The possible reason of burner to undergoes surface or submerged flame mainly depends on availability of oxygen and surface area to perform combustion. Furthermore Fig. 8 indicate the actual photographic images of alumina at 0.7 and $0.6 \mathrm{ER}$. Thermal images are used to capture the temperature distribution at critical ER. With the help thermal imager generated photographic images indicate the sniped overview of temperature variation on the burner wall for alumina and zirconia as shown in Fig. 9 and 10. Maximum thermal efficiency was calculated during surface flame was recorded as $84 \%$ and $77 \%$ for alumina and zirconia respectively. Finally, with the help of certified gas analyser, emitted emissions from the burner surface where fed to gas probe to measure NOx and CO. It was found out that emission where less than $1 \mathrm{ppm}$ since the minimum amount to detect the ppm for the utilized gas analyser is $1 \mathrm{pmm}$.

\section{Conclusions}

Presented experimental work deal with comparative study between alumina and zirconia porous media in reaction zone. With Alumina in reaction zone better temperature profiles were obtained. At least 7\% more thermal efficiency was noted in comparison with zirconia. Trails were conducted with both surface and submerged flame based on various ER from lean to ultra-lean ER. Predefined thickness of reaction and preheat layer was used to performed combustion. Optimum ER for surface flames and submerged flame are 0.7 and 0.6 respectively. Maximum temperature recorded at best performing ER was $631^{\circ} \mathrm{C}$ leading to thermal efficiency of $84 \%$. 
Emission parameters such NOx and $\mathrm{CO}$ where less than $1 \mathrm{ppm}$.

\section{References}

1. Udayraj, et al., Heat and mass transfer through thermal protective clothing - A review. International Journal of Thermal Sciences, 2016. 106: p. 32-56.

2. Jiang, X., D. Mira, and D.L. Cluff, The combustion mitigation of methane as a non- $\mathrm{CO} 2$ greenhouse gas. Progress in Energy and Combustion Science, 2016.

3. Arya, P.K., et al., DME blended LPG as a cooking fuel option for Indian household: A review. Renewable \& Sustainable Energy Reviews, 2016. 53: p. 1591-1601.

4. Daneshvar, H., R. Prinja, and N.P. Kherani, Thermophotovoltaics: Fundamentals, challenges and prospects. Applied Energy, 2015. 159: p. 560-575.

5. Al-Abdeli, Y.M. and A.R. Masri, Review of laboratory swirl burners and experiments for model validation. Experimental Thermal and Fluid Science, 2015. 69: p. 178-196.

6. Zanganeh, J., B. Moghtaderi, and H. Ishida, Combustion and flame spread on fuel-soaked porous solids. Progress in Energy and Combustion Science, 2013. 39(4): p. 320-339.

7. Mujeebu, M.A., et al., Combustion in porous media and its applications--a comprehensive survey. J Environ Manage, 2009. 90(8): p. 2287-312.
8. Mujeebu, M.A., et al., Applications of porous media combustion technology - A review. Applied Energy, 2009. 86(9): p. 1365-1375.

9. Mujeebu, M.A., et al., A review of investigations on liquid fuel combustion in porous inert media. Progress in Energy and Combustion Science, 2009. 35(2): p. 216-230.

10. Zuo, W., et al., Numerical investigations on combustion characteristics of $\mathrm{H} 2$ /air premixed combustion in a micro elliptical tube combustor. Energy, 2017. 126: p. 1-12.

11. Panigrahy, S., et al., Numerical and experimental analyses of LPG (liquefied petroleum gas) combustion in a domestic cooking stove with a porous radiant burner. Energy, 2016. 95: p. 404-414.

12. Mustafa, K.F., et al., Comparative assessment of a porous burner using vegetable cooking oil-kerosene fuel blends for thermoelectric and thermophotovoltaic power generation. Fuel, 2016. 180: p. 137-147.

13. Ismail, A.K., et al., Application of porous medium burner with micro cogeneration system. Energy, 2013. 50: p. 131-142.

14. Janvekar, A.A., et al., Effects of the preheat layer thickness on surface/submerged flame during porous media combustion of micro burner. Energy, 2017. 122: p. 103-110.

15. Janvekar, A.A., et al. Assessment of porous media burner for surface/submerged flame during porous media combustion. in AIP Conference Proceedings. 2017. AIP Publishing. 